Research paper

\title{
Sodium montmorillonite/ureasil-poly(oxyethylene) nanocomposite as potential adsorbent of cationic dye
}

\author{
Yanisleidys Hernández Bermúdez*, Laurianne Truffault, Sandra Helena Pulcinelli, \\ Celso Valentim Santilli \\ Universidade Estadual Paulista “Júlio de Mesquita Filho”, Istituto de Química, Rua Prof. Francisco Degni 55, 14800-900, São Paulo, Araraquara, Brazil
}

\section{A R T I C L E I N F O}

\section{Keywords:}

Montmorillonite

Nanocomposite

Dye

Adsorption

Water decontamination

\begin{abstract}
A B S T R A C T
A sodium montmorillonite/ureasil-poly(oxyethylene) clay-polymer nanocomposite was prepared using the solgel reaction of a U-PEO hybrid precursor/clay mineral suspension, with the aim of developing a sorbent for the removal of cationic dyes from aqueous media. The structural characteristics of the nanocomposite were studied by FTIR, XRD, UV-Vis spectroscopy, and SAXS. The XRD results revealed intercalation of the U-PEO in the silicate interlayer spaces. FTIR spectra indicated the existence of strong interactions between methylene blue (MB) dye and the clay mineral silicate layers. Time-resolved SAXS measurements during MB adsorption showed a decrease of the montmorillonite (Mt) peak area and an increase of the half-height width of the peak, indicating that water uptake during dye adsorption caused a reduction of the Mt. crystallite size. UV-Vis adsorption experiments showed that the kinetics of $\mathrm{MB}$ adsorption followed a pseudo-first order process and that the steady state equilibrium adsorption capacity followed the Langmuir model. The results showed that the nanocomposite is potentially applicable as an adsorbent of dyes present in contaminated waters.
\end{abstract}

\section{Introduction}

The development of science and technology has provided clear benefits to society, but at the same time has led to many environmental problems, such as contamination by effluents, air pollution, and climate change, among others. In addition to the fact that the availability of fresh water is decreasing due to high consumption by agriculture (70\%), industry (22\%), and households (8\%) (Bhatnagar and Sillanpää, 2010), the wastewater that returns to the environment contains various contaminants, such as heavy metals or dyes, which are often difficult to biodegrade and are toxic to animals and humans (Aguiar et al., 2017). Different physical, chemical, electrochemical, and biological methods can be used to treat and reuse wastewater (Crini, 2006; Hajjaji et al., 2016). Among the physical-chemical methods, adsorption processes are of particular interest due to their speed, nontoxicity, relatively low cost, and efficiency in the removal of pollutants and treatment of large volumes of liquids (Allègre et al., 2006; dos Santos et al., 2017; Unuabonah and Taubert, 2014).

Recent studies of dye adsorption have shown that urea-cross-linked siloxane (ureasil)-polyether (U-PE) materials are efficient dye adsorbents (Bekiari and Lianos, 2006; Molina et al., 2014; Moura et al., 2015). Compared to mineral and polymeric materials in the form of powders, such as clays, manganese oxide, silica, alumina, and chitosan,
U-PE hybrid materials are easier to recover from wastewater due to their rubbery nature, flexibility, and insolubility in water (Santilli et al., 2009). Bekiari and Lianos (2006) synthesized ureasil-poly(oxypropylene) (U-PPO) with molar masses of 4000, 2000, and $230 \mathrm{~g} \mathrm{~mol}^{-1}$ and ureasil-PPO-block-poly-oxyethylene (PEO-block-PPO) with molar masses of 1900,800 , and $500 \mathrm{~g} \mathrm{~mol}^{-1}$, for application in dye adsorption. The materials were shown to efficiently adsorb dyes, with the highest efficiency of adsorption of acid orange 7 dye achieved using UPPO with molar mass of $230 \mathrm{~g} \mathrm{~mol}^{-1}$. More recently, Molina et al. (2014) demonstrated that U-PEO with molar mass of $500 \mathrm{~g} \mathrm{~mol}^{-1}$ provided selective adsorption of anionic dyes, rather than cationic dyes. In other work, hybrid matrices composed of 3-glycidoxypropyl-trimethoxysilane (GPMS) linked to end-group functionalized polyetheramines (U-PEO and U-PPO) showed good adsorption capacity (415 $\mathrm{mg} \mathrm{g}^{-1}$ ) for the rose bengal anionic dye (Moura et al., 2015). Montmorillonite (Mt) is an efficient adsorbent of cationic dyes such as methylene blue (MB), crystal violet, methyl violet, basic blue 16, and others (Aladağ et al., 2014; Almeida et al., 2009; Fil et al., 2012; Gunay et al., 2013; Zhu et al., 2014). Dye adsorption by Mt. usually occurs by means of electrostatic interactions (Aladağ et al., 2014; Hegyesi et al., 2017).

In this work, we describe the development of a novel U-PEO hybrid nanocomposite with both anionic and cationic adsorption properties,

\footnotetext{
* Corresponding author.

E-mail address: yania@iq.unesp.br (Y.H. Bermúdez).
} 
which can be easily recovered at the end of the adsorption process. The incorporation of sodium Mt. during the sol-gel synthesis of a U-PEO hybrid resulted in the formation of a rubbery sodium montmorillonite/ ureasil-poly(oxyethylene) clay-polymer nanocomposite (CPN). The structural features of the hybrid nanocomposite were studied by X-ray diffraction and infrared spectroscopy. The evolution of the nanostructure during the adsorption process was investigated by in situ SAXS. The adsorption process was quantitatively monitored using UV-Vis spectroscopy.

\section{Materials and methods}

\subsection{Synthesis of the hybrid precursor}

A $10.4 \mathrm{~mL}$ volume of 3-isocyanatopropyltriethoxysilane (ICPTES) (Sigma-Aldrich, 95\%) was mixed with $40 \mathrm{~g}$ of O,O'-bis(2-aminopropyl)polypropylene glycol-block-polyethylene glycol-block-polypropylene glycol (molar mass $=1900 \mathrm{~g} \mathrm{~mol}^{-1}$ ) (Fluka) in $150 \mathrm{~mL}$ of tetrahydrofuran (Synth) as solvent. The mixture was refluxed for $24 \mathrm{~h}$ at $78^{\circ} \mathrm{C}$. At the end of the reaction, the solvent was removed using rotary evaporation at $60{ }^{\circ} \mathrm{C}$, producing the hybrid precursor (Santilli et al., 2009).

\subsection{Incorporation of clay mineral in the hybrid matrix}

A $0.3 \mathrm{~g}$ mass of Mt. (Southern Clay Products) was mixed with $3.0 \mathrm{~mL}$ of anhydrous ethanol (Sigma-Aldrich), under sonication (Vibracel VC 501) for 2 min to improve dispersion of the Mt. The dispersion was transferred to a beaker containing $1.5 \mathrm{~g}$ of the hybrid precursor and the sol-gel reactions were then induced by adding $100 \mu \mathrm{L}$ of distilled water, under mechanical stirring for $4 \mathrm{~h}$, followed by addition of $36 \mu \mathrm{L}$ of $2 \mathrm{M} \mathrm{HCl}$ (Mallinckrodt) as catalyst. Drying at room temperature in a desiccator under vacuum resulted in disk-shaped monolithic xerogels $\sim 25 \mathrm{~mm}$ in diameter and $\sim 1 \mathrm{~mm}$ in height.

\subsection{Characterizations}

Fourier transform infrared spectroscopy (FTIR) analyses were performed using a Bruker VERTEX 70 instrument equipped with a DLaTGS detector and operated in attenuated total reflection mode. $\mathrm{KBr}$ pellets containing $1 \%(\mathrm{~m} / \mathrm{m})$ of sample were analyzed in the spectral range $4000-400 \mathrm{~cm}^{-1}$, with $4 \mathrm{~cm}^{-1}$ resolution and 64 scans.

$\mathrm{X}$-ray powder diffraction (XRD) was used to study the crystalline structure of the CPN and evaluate the intercalation and exfoliation of the Mt. dispersed in the U-PEO hybrid matrix. The XRD measurements were performed using a Siemens D5000 diffractometer operated with CuK $\alpha$ radiation $(\lambda=1.5405 \AA)$ monochromatized using a curved graphite single crystal, $6.0 \mathrm{~mm}$ detector slits, and $2 \theta$ from 2 to $70^{\circ}$, with a $0.02^{\circ}$ step every $3 \mathrm{~s}$.

Methylene blue (Sigma-Aldrich) was used in the adsorption study as-received, without further purification. The evolution of the MB concentration in the supernatant solution during the adsorption process was monitored by UV-Vis absorption spectrophotometry using the MB monomer band $\left(\lambda_{\max }=665 \mathrm{~nm}\right)$. It is important to note that the UV-Vis spectra (Fig SI1, Supplementary information) of MB supernatant solution after the adsorption equilibrium display an invariant shape with a maximum at $\lambda=665 \mathrm{~nm}$, a shoulder at $\lambda=615 \mathrm{~nm}$ corresponding to the vibronic transition and any evidence of the MB dimer band at $605 \mathrm{~nm}$ (Bergmann and O'Konski, 1963). Moreover, the ratio between the amplitude of the main band and the shoulder stays constant $\left(\mathrm{A}_{665} / \mathrm{A}_{615}=2.0 \pm 01\right)$, confirming the negligible contribution of $\mathrm{MB}$ dimer $\left(\lambda_{\max }=605 \mathrm{~nm}\right)$ to the $\mathrm{MB}$ monomer absorption spectra. Under this condition the concentration of the MB monomer could be determined from the experimental analytical curve presented in Fig. SI2. For the isothermal absorption experiments approximately $0.01 \mathrm{~g}$ portions of the CPN were immersed in $60 \mathrm{~mL}$ of aqueous solution containing $\mathrm{MB}$ at different concentrations $(\sim 4,5,6,7,8,9$, and $10 \mathrm{mg} \mathrm{L}^{-1}$ ). The samples were agitated in a temperature-controlled reciprocating shaker bath at $25{ }^{\circ} \mathrm{C}$ for $36 \mathrm{~h}$. During this period, the dye concentration $\left(C_{t}\right)$ in the supernatant solution was analyzed at regular intervals using a Cary 60 UV-Vis spectrophotometer equipped with a $10 \mathrm{~mm}$ immersion probe. The mass of dye adsorbed per gram of CPN, $q_{t}$ $\left(\mathrm{mg} \mathrm{g}^{-1}\right)$, was calculated as a function of immersion time according to:

$q_{t}=V \frac{\left(C_{o}-C_{t}\right)}{m}$

where $C_{O}$ is the initial dye concentration $\left(\mathrm{mg} \mathrm{L}^{-1}\right), V$ is the dye solution volume $(\mathrm{mL})$, and $m$ is the CPN mass $(\mathrm{g})$.

The nanostructures of the dry nanocomposites and their evolution during dye adsorption were monitored in situ using small angle X-ray scattering (SAXS). The measurements were performed at the SAXS 1 beamline of the National Synchrotron Light Laboratory (LNLS, Campinas, Brazil). For the adsorption process, the sample was placed in a liquid sample cell and $5 \mathrm{~mL}$ of aqueous $\mathrm{MB}$ dye solution was added with a syringe, at room temperature $\left(25 \pm 1{ }^{\circ} \mathrm{C}\right)$. A monochromatic beam $(\lambda=1.550 \AA$ ) and a bidimensional detector (PILATUS $300 \mathrm{~K}$ ) located at a distance of $900.55 \mathrm{~mm}$ from the sample were used to measure the scattering intensity, I(q), according to the modulus of the scattering vector: $q=(4 \pi / \lambda) / \sin (\theta / 2)$, where $\theta$ is the scattering angle and $\lambda$ is the radiation wavelength. SAXS data were acquired during $4 \mathrm{~s}$, every $26 \mathrm{~s}$, during the first and the last hours of adsorption.

\section{Results and discussion}

\subsection{Structural features}

Fig. 1a shows a comparison of the infrared spectra of pristine MB, Mt., and U-PEO, together with those for the hybrid nanocomposites (CPN:MB and Mt.:MB) after dye adsorption $\left(10 \mathrm{mg} \mathrm{L}^{-1}\right)$. The CPN:MB spectrum presented the characteristic U-PEO bands centered at 3355 ( $\nu \mathrm{NH}, \mathrm{H}$-bonded), $2951\left(\nu_{\mathrm{a}} \mathrm{CH}_{2}\right), 2866\left(\nu_{\mathrm{s}} \mathrm{CH}_{3}\right), 1642,1560,1455\left(\mathrm{CH}_{2}\right.$ scissoring), $1347\left(\mathrm{CH}_{2}\right.$ wagging), $1241\left(\mathrm{CH}_{2}\right.$ twisting), $1092(\nu \mathrm{CO})$, $1037\left(\nu \mathrm{CO}, \nu \mathrm{CC}, \mathrm{rCH}_{2}\right), 941\left(\nu \mathrm{CC}, \mathrm{rCH}_{2}\right)$ and $844 \mathrm{~cm}^{-1}\left(\nu \mathrm{CO}, \mathrm{rCH}_{2}\right)(\mathrm{de}$ Zea Bermudez et al., 1999). The weak band located at $3355 \mathrm{~cm}^{-1}$ is an overtone of the band at $1560 \mathrm{~cm}^{-1}$ attributed to the so called amides II, while the band at $1642 \mathrm{~cm}^{-1}$ is related to the so called amides I (Pavia et al., 2012). The absorption due to the symmetrical stretching vibration of the Si-O-Si of U-PEO siloxane nodes, occurring in the 950 to $1150 \mathrm{~cm}^{-1}$ range, are masked by the very intense $\mathrm{C}-\mathrm{O}$ stretching absorption $\left(1092 \mathrm{~cm}^{-1}\right)$ and the strong coupled vibrations of the $\mathrm{C}-\mathrm{C}$ stretching and $\mathrm{CH}_{2}$ rocking $\left(1037 \mathrm{~cm}^{-1}\right)$ modes that fall in the same range of frequencies (de Zea Bermudez et al., 1999).

The presence of the Mt. in the Mt.: MB and CPN:MB samples was evidenced by the characteristic Mt. bands located at 3625, 516, and $448 \mathrm{~cm}^{-1}$ (Madejová, 2003; Validi et al., 2012). The band at $3625 \mathrm{~cm}^{-1}$ was assigned to the stretching vibration of structural $\mathrm{OH}$ bonded to $\mathrm{Al}$ or $\mathrm{Mg}$. Bands at 516 and $448 \mathrm{~cm}^{-1}$ were assigned to $\mathrm{Al}-\mathrm{O}-$ $\mathrm{Si}$ and Si-O-Si bending vibrations, respectively (Chieng et al., 2010; Validi et al., 2012). Comparison of the CPN:MB and Mt.:MB spectra to the MB spectrum revealed major changes, as shown for the amplified $900-1700 \mathrm{~cm}^{-1}$ region (Fig. 1b). The band centered at around $1383 \mathrm{~cm}^{-1}$ in the $\mathrm{MB}$ spectrum, attributed to the $\mathrm{C}=\mathrm{S}$ bond (Kariminezhad et al., 2015), appeared at $1391 \mathrm{~cm}^{-1}$ and $1385 \mathrm{~cm}^{-1}$ in the CPN:MB and Mt.:MB spectra, respectively. Similarly, the band located at $1590 \mathrm{~cm}^{-1}$ in the dye spectrum, assigned to aromatic ring $\mathrm{C}=\mathrm{C}$ vibration (Àngels Olivella et al., 2012; Validi et al., 2012), was shifted to higher energies of 1600 and $1605 \mathrm{~cm}^{-1}$ in the CPN:MB and Mt.:MB spectra, respectively. The band centered at $1484 \mathrm{~cm}^{-1}$ in the dye spectrum, attributed to symmetric $\mathrm{C}=\mathrm{N}$ stretching vibration (Feng et al., 2013; Validi et al., 2012), showed blue shifts to 1487 and $1498 \mathrm{~cm}^{-1}$ in the CPN:MB and Mt.:MB spectra, respectively. These shifts indicate the existence of strong interactions between the MB dye 

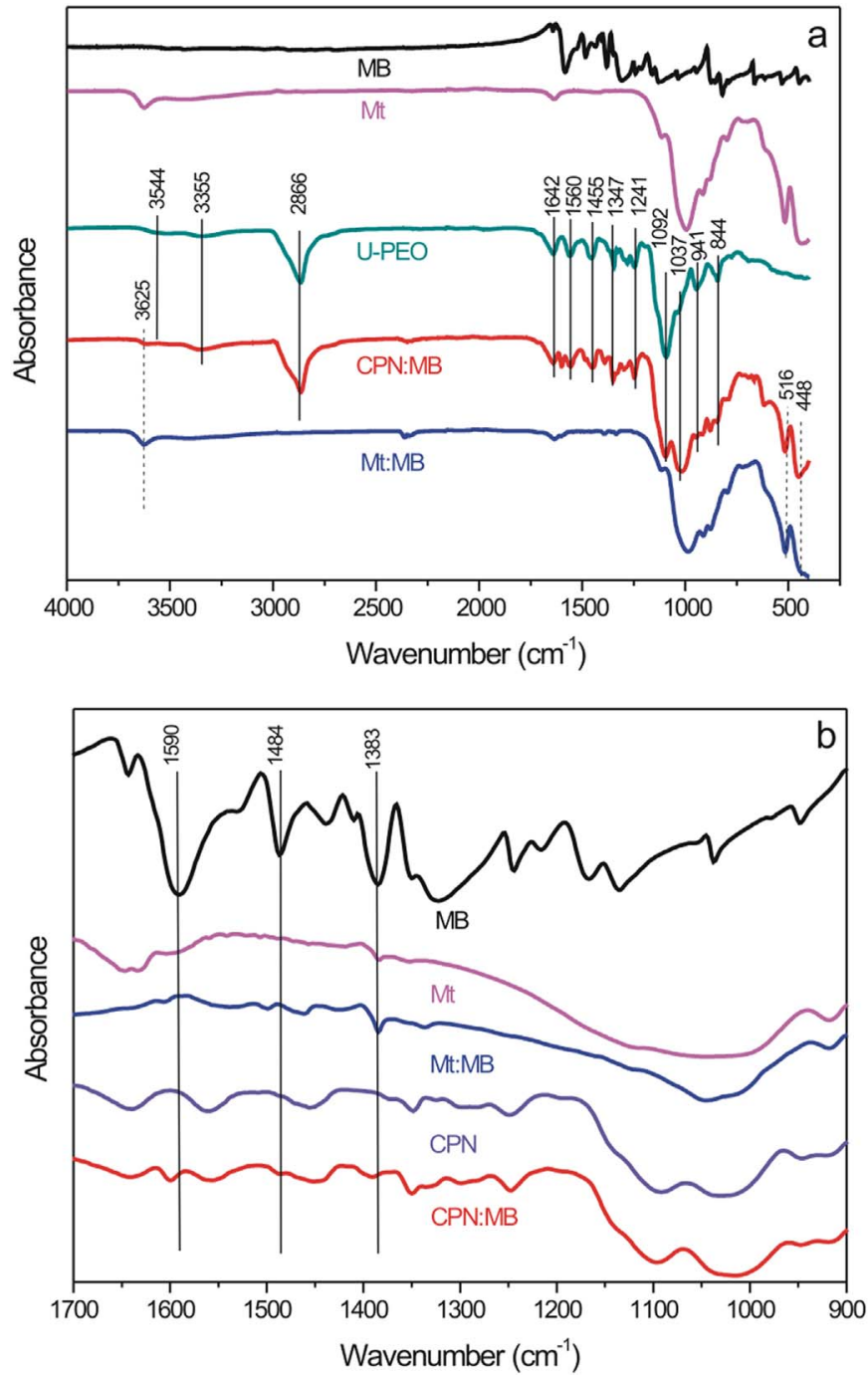

Fig. 1. (a) FTIR spectra of the MB, Mt., U-PEO, CPN:MB, and Mt::MB samples in the $4000-400 \mathrm{~cm}^{-1}$ region; (b) FTIR spectra of the MB, Mt., Mt.:MB, CPN, and CPN:MB samples in the $1700-900 \mathrm{~cm}^{-1}$ region.

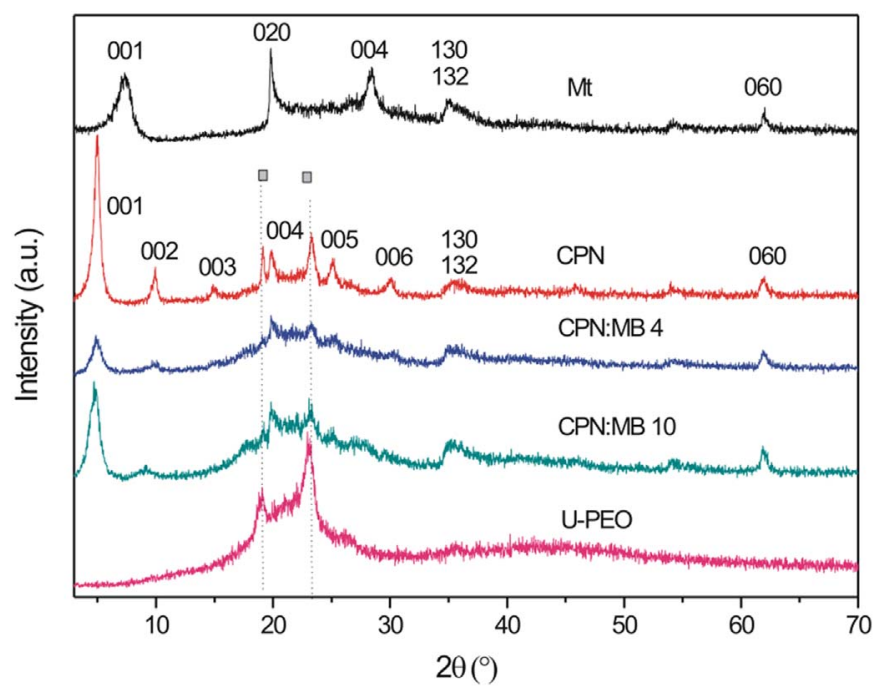

Fig. 2. XRD patterns of Mt., CPN, CPN:MB (4 and $10 \mathrm{mg} \mathrm{L}^{-1}$ ), and U-PEO.
Table 1

Positions and corresponding interlayer spaces for the (001) basal reflections of Mt., CPN, and CPN: MB (4 and $10 \mathrm{mg} \mathrm{L}^{-1}$ ).

\begin{tabular}{lcc}
\hline Sample & $2 \theta\left({ }^{\circ}\right)$ & $\mathrm{d}_{(001)}(\AA)$ \\
\hline Mt & 7.34 & 12.04 \\
CPN & 4.95 & 17.84 \\
CPN:MB 4 & 4.88 & 18.09 \\
CPN:MB 10 & 4.74 & 18.63 \\
\hline
\end{tabular}

and the silicate layers of the clay mineral (Validi et al., 2012).

The XRD patterns of Mt., U-PEO, CPN, and CPN:MB are shown in Fig. 2. The U-PEO hybrid displayed two reflections at 19 and $23^{\circ}$, characteristic of the semi-crystalline PEO, superimposed on a broad band (Hikosaka et al., 2006). The diffraction patterns of the nanocomposites exhibited greater numbers of high order diffraction peaks ((002), (003), (004), (005), (006)) as compared to the pristine Mt. one. The narrowing of the (001) peak of Mt. in the nanocomposite and the similar breadth of the higher order peak ((002), (004) and (005)) evidence a low internal disorder in the stacking layer structure. Moreover, the higher relative intensity of (001) diffraction peak indicates a preferential orientation of Mt. platelets along the c-axis after dispersion of the clay mineral in the U-PEO. In addition to the characteristic Mt. peaks, the nanocomposite diffractograms displayed reflections characteristic of semi-crystalline PEO. Incorporation of the clay mineral into the U-PEO caused a shift of the basal reflection (001) of pristine Mt. to a lower $2 \theta$ angle, from $7.34^{\circ}(\mathrm{Mt})$ to $4.95^{\circ}(\mathrm{CPN})$. This corresponded to an increase of the $(001)$ interlayer space $\left(\mathrm{d}_{001}\right)$ from $12.04 \AA$ (Mt) to $17.84 \AA$ (CPN) (see Table 1), evidencing the intercalation of PEO chains of the hybrid frameworks in the interlayer spaces between the silicate layers. From the difference between the thicknesses of the silicate layer $(\sim 9.5 \AA)$ and the interlayer space of embedded Mt., $\Delta \mathrm{d}_{001}$ of $\sim 8.34 \AA$ was estimated for the interlayer space with intercalated polymer molecules. This interlayer space was compatible with the intercalation of two monolayers of PEO molecules in planar zig-zag conformation, or one PEO monolayer in helicoidal conformation (Strawhecker and Manias, 2003). Increases of this interlayer space to 18.09 and $18.63 \AA$ were observed after the attainment of steady state adsorption equilibria for the nanocomposites immersed in aqueous solutions containing 4 and $10 \mathrm{mg} \mathrm{L}^{-1}$ of $\mathrm{MB}$, respectively. These small increases of the interlayer space could not be explained by the additive intercalation of MB molecules in the interlayer space of Mt. This phenomenon, which was probably associated with water uptake, is discussed further below.

\subsection{Removal of dye from water}

The capacity of the CPN to remove MB from aqueous solutions containing different initial dye concentrations $(\sim 4,5,6,7,8,9$, and $10 \mathrm{mg} \mathrm{L}^{-1}$ ) is displayed in Fig. 3a. Irrespective of the initial concentration, the curves showed that the CPN removed $>45 \%$ of the dye after $24 \mathrm{~h}$ of immersion, indicating a moderate adsorption capacity. After $58 \mathrm{~h}$, the system reached steady state equilibrium, with the removal exceeding $69 \%$. In contrast, the MB concentrations $(\sim 4,6$, and $9 \mathrm{mg} \mathrm{L}^{-1}$ ) remained unaltered during contact with the U-PEO (Fig. 3b), confirming that there was no adsorption of cationic dye by the hybrid matrix. For illustrative purposes, the inset of Fig. 3a shows that the CPN color changed from yellow (before adsorption) to intense blue after $72 \mathrm{~h}$ of immersion in MB solution. In contrast, the transparency of the U-PEO remained almost unchanged after several days (1-3) of immersion in the solution, showing that the hybrid matrix did not adsorb MB (Fig. 3b). The light blue color was due to the presence of the dye molecules on the external surfaces of the U-PEO monoliths. Following immersion in water, it is likely that the amine groups of U-PEO acquired positive charges that hindered their interaction with the positively charged dye molecules. This feature confirmed that adsorption of the cationic dye occurred at the negatively charged surfaces of the clay 

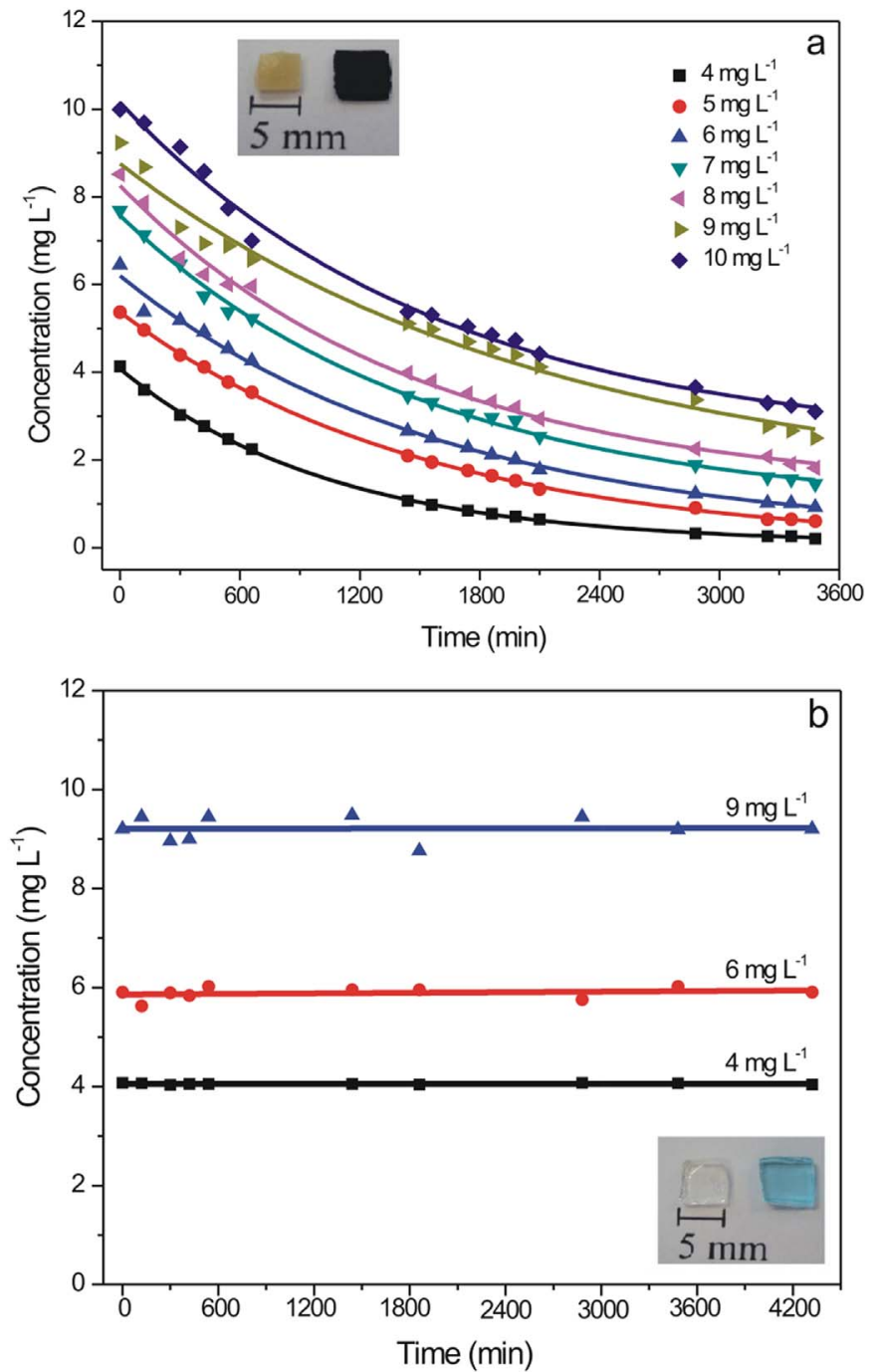

Fig. 3. Temporal evolution of MB concentrations during adsorption. The continuous and dashed lines connect the experimental data for adsorption by (a) CPN and (b) U-PEO. The pictures show the CPN (top) and the U-PEO (bottom), before (left) and after (right) immersion in the dye solution.

mineral nanoparticles dispersed in the nanocomposite matrix (Zhang et al., 2014). Moreover, both materials (CPN and U-PEO) showed similar macroscopic swelling of $\sim 44 \mathrm{wt} \%$, due to water uptake by the hybrid matrix, indicating that the hydrogel behavior of the hydrophilic U-PEO network was essentially unaffected by the incorporation of Mt.

\subsection{Nanostructural evolution during dye removal}

The effect of incorporation of Mt. in the U-PEO on the nanostructure of the nanocomposite was analyzed using ex situ SAXS. Time-resolved SAXS monitoring was used to assess the effects of water uptake and dye adsorption on the hybrid matrix and the dispersed Mt. phase. The ex situ measurements employed the dry materials before and after dye adsorption, while in situ experiments were performed with samples immersed in aqueous dye solutions and in water.

The SAXS curves of the dry U-PEO, Mt., and CPN samples, before and after adsorption of $\mathrm{MB}$ (at $10 \mathrm{mg} \mathrm{L}^{-1}$ ) are compared in the log-log graph displayed in Fig. 4. The SAXS curve of the U-PEO hybrid showed a broad peak with a maximum at $\sim 1.47 \mathrm{~nm}^{-1}$, due to an interference effect in the X-ray scattering amplitude produced by the existence of spatially correlated ureasil cross-linked nodes at both the ends of the PEO chains (Chaker et al., 2006). An average distance $\left(d_{s}\right)$ of $4.3 \mathrm{~nm}$

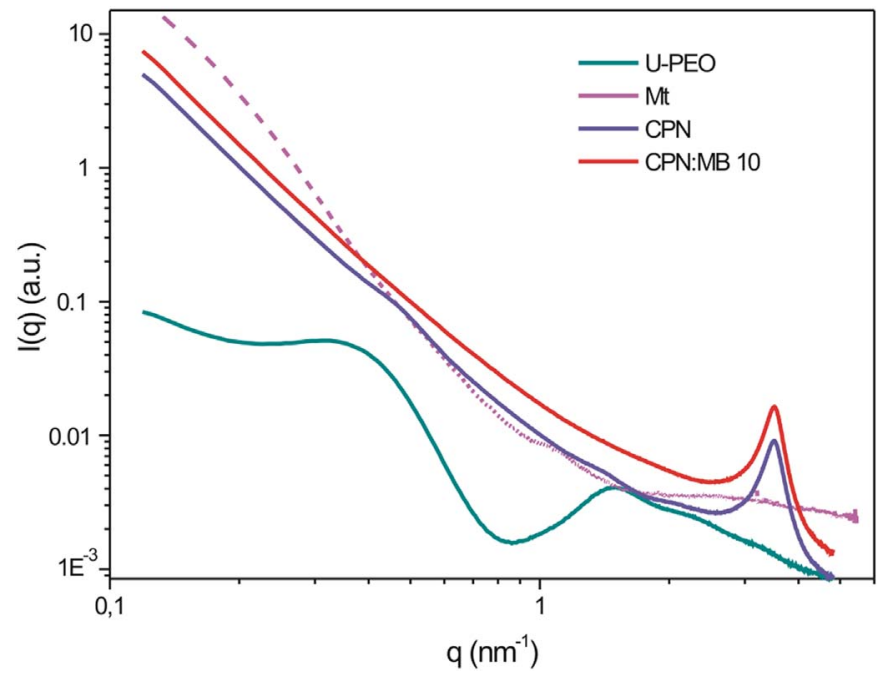

Fig. 4. SAXS patterns of the dry U-PEO, Mt., and CPN samples, before and after MB adsorption from solutions containing $10 \mathrm{mg} \mathrm{L}^{-1}$ of the dye.

between the cross-linked nodes was calculated from the peak position $\left(d_{s}=2 \pi / q_{\max }\right)$. A second peak was observed at lower $q$ values, with a maximum $\left(\mathrm{q}_{\max }\right)$ at $\sim 0.38 \mathrm{~nm}^{-1}$, corresponding to a Bragg distance of $16.5 \mathrm{~nm}$, typical of the interlayer distance of the crystalline PEO homopolymer (Hikosaka et al., 2006). However, the absence of higher order reflections was characteristic of scattering by a mesoscopic arrangement with smaller size.

The basal reflection corresponding to the Mt. interlayer distance was not apparent in the SAXS curve of Mt., because the (001) basal reflection occurs at $\mathrm{q}=5.3 \mathrm{~nm}^{-1}$ and was therefore above the maximum q value provided by the experimental system. The CPN samples presented similar patterns before and after MB adsorption, with peaks centered at $3.5 \mathrm{~nm}^{-1}$. In agreement with the XRD results, this shift of the (001) Mt. peak towards smaller angles evidenced the intercalation of PEO between the Mt. silicate layers. Additionally, the U-PEO correlation peak was absent in the SAXS curves of the nanocomposites. This was probably due to the fact that Mt. scatters X-rays more efficiently than U-PEO, so its scattering contribution dominated the nanocomposite SAXS curves. At lower q values, the CPN SAXS curves displayed linear behavior characteristic of power law decay of the scattering intensity $\left(\mathrm{I}(\mathrm{q}) \propto \mathrm{q}^{-\alpha}\right)$. The slopes of these linear regions corresponded to $\alpha$ of $\sim 2.9-3.1$, indicating the presence of dense aggregates (Brinker and Scherer, 1990). As the scattering intensity followed this power law from the smallest $q$ value used in the SAXS experiments, it was impossible to reach the $\mathrm{q}$ region for which the Guinier law is valid (Brinker and Scherer, 1990). This also implied that the q range employed actually probed the interior of the Mt. tactoids. The value of the exponent ( $\alpha \approx 2.9-3.1$ ) was lower than 4 , as expected from the Porod behavior (Brinker and Scherer, 1990) of a two-electron density system with smooth interfaces. The observed behavior indicated that the Mt. tactoids did not satisfy the two-electron density model, probably due to the large electron density difference between the silicate layer and the interlayer space.

Fig. 5 displays a three-dimensional stacked line plot of the SAXS curves as a function of time of immersion of CPN in the dye solution (Fig. 5a) and in pure water (Fig. 5b), during the first hour of immersion. The position of the (001) Mt. peak remained essentially invariant, while the intensity clearly decreased during the first hour. In order to quantify the nanostructural changes occurring during the immersion and adsorption of water and dye, calculation was made of the temporal evolutions of the area and full width at half maximum (FWHM) of the Mt. basal reflection, and of the slope of the linear region in the low q range. As shown in Fig. 6a, the Mt. relative peak area decreased continuously during the first $30 \mathrm{~min}$ and then reached a constant value. Similar peak 

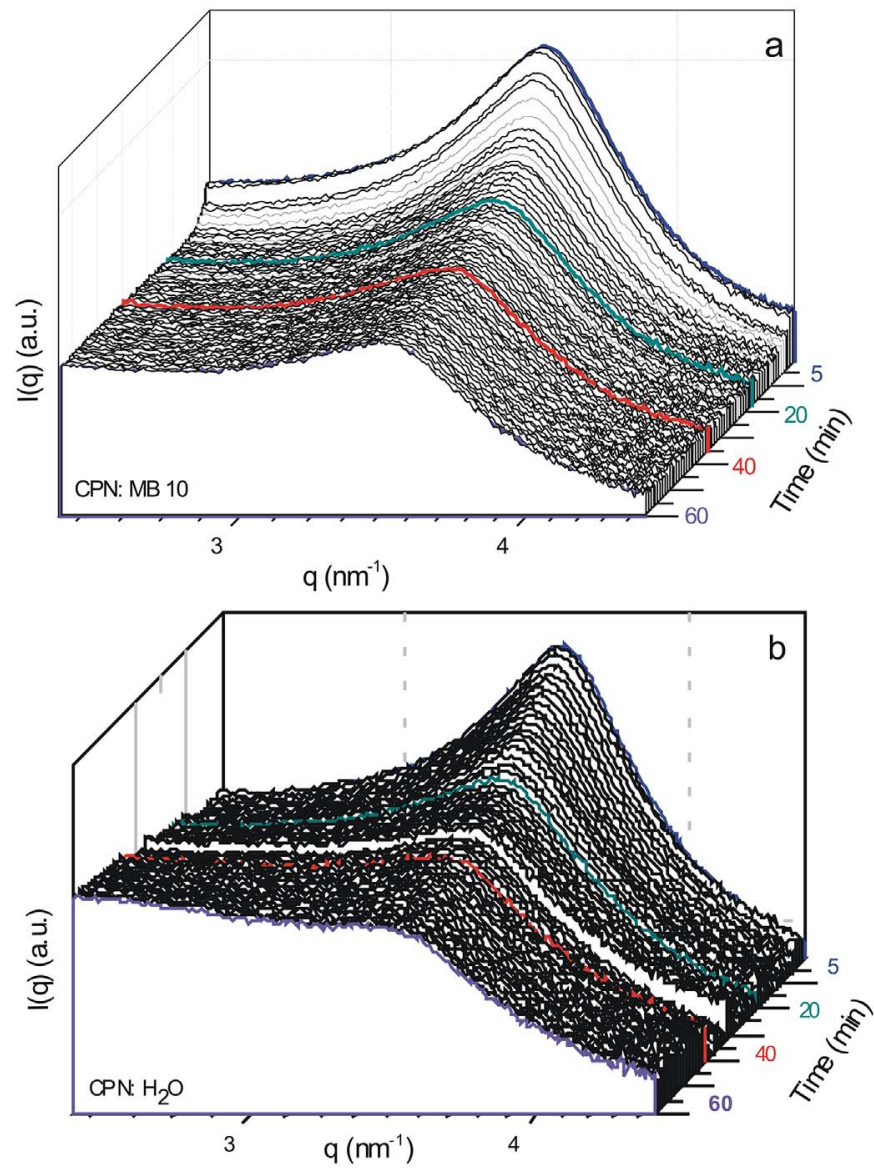

Fig. 5. Temporal evolution of SAXS patterns during the first hour of immersion of the $\mathrm{CPN}$ in (a) dye solution $\left(10 \mathrm{mg} \mathrm{L}^{-1}\right)$ and (b) water.

area decreases were observed for CPN immersed in water and in dye solution, indicating that this phenomenon was due to water uptake, rather than dye adsorption. However, notable features for adsorption of the dye solution were an initial induction period and greater continuity of the sigmoidal decay. The former could have been related to osmotic stretching, while the latter could have been due to ion exchange between the Mt. cations $\left(\mathrm{Na}^{+}\right)$and the cationic MB dye. This process was accompanied by an increase of the FWHM (Fig. 6b), indicating a reduction of the Mt. crystallite size. This finding suggested that the water uptake promoted a decrease of the number of silicate layers forming the periodic packing along the $\mathrm{c}$-axis of the tactoids. Moreover, the slope of the Porod regime increased continuously during the first $30 \mathrm{~min}$ of the immersion and evolved asymptotically to a plateau after $60 \mathrm{~min}$ (Fig. 6c). The slope modulus values of $2.68 \pm 0.03$ obtained for the initial times of immersion of the CPN in water and in dye solution indicated the existence of fractal aggregates with dimensionality $\left(D_{m}\right)$ of $2.68 \pm 0.03$ (Brinker and Scherer, 1990). After the initial decreases, the slopes reached constant values corresponding to $D_{m}$ of $2.46 \pm 0.02$ and $2.38 \pm 0.02$ for the nanocomposites immersed in water and in dye solution, respectively. This behavior evidenced evolution of the Mt. layers packing from a dense to a more open aggregate structure, due to partial exfoliation of the crystallites.

\subsection{Kinetics of $M B$ adsorption}

The temporal evolutions of the mass of adsorbed dye $\left(q_{t}\right.$, calculated using Eq. 1) are plotted in Fig. 7. The adsorption capacity of the CPN sample increased with the time of contact with the dye, as well as with the concentration of cationic dye in the initial solution. The highest $\mathrm{q}_{\mathrm{t}}$ values $\left(37-38 \mathrm{mg} \mathrm{g}^{-1}\right.$ ) were obtained for dye concentrations of
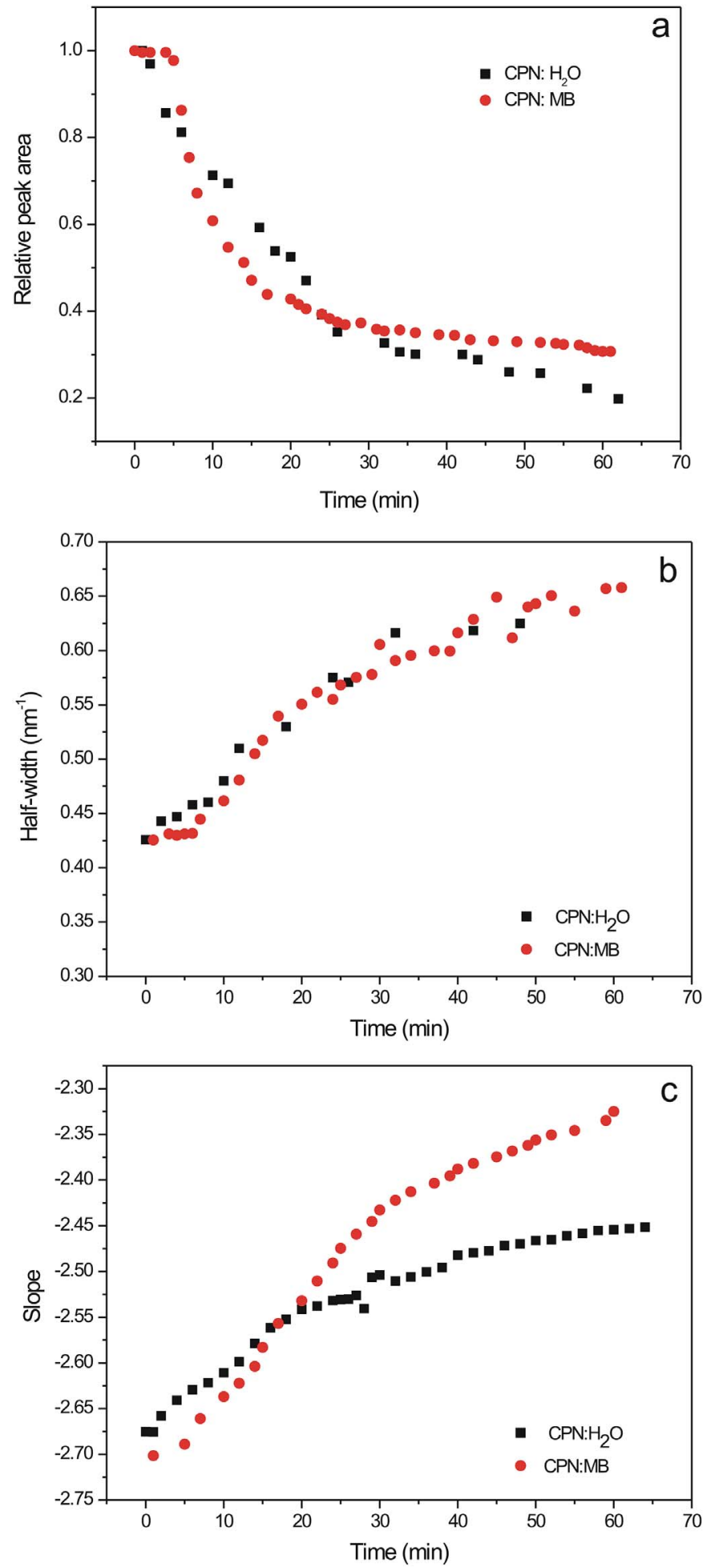

Fig. 6. Temporal evolution of the (001) Mt. diffraction peak: (a) relative peak area, (b) FWHM, and (c) Porod region slope during the first hour of immersion of the CPN in MB dye solution (black) and in water (red). (For interpretation of the references to color in this figure legend, the reader is referred to the web version of this article.)

8-10 $\mathrm{mg} \mathrm{L}^{-1}$. These values were fifteen times higher than the equilibrium adsorption capacities reported previously for anionic dyes (orange II and ponceau) adsorbed using a similar U-PEO hybrid material (Molina et al., 2014).

In order to further elucidate the adsorption mechanism, pseudo-first order (Eq. 2) and pseudo-second order (Eq. 3) models were employed to 

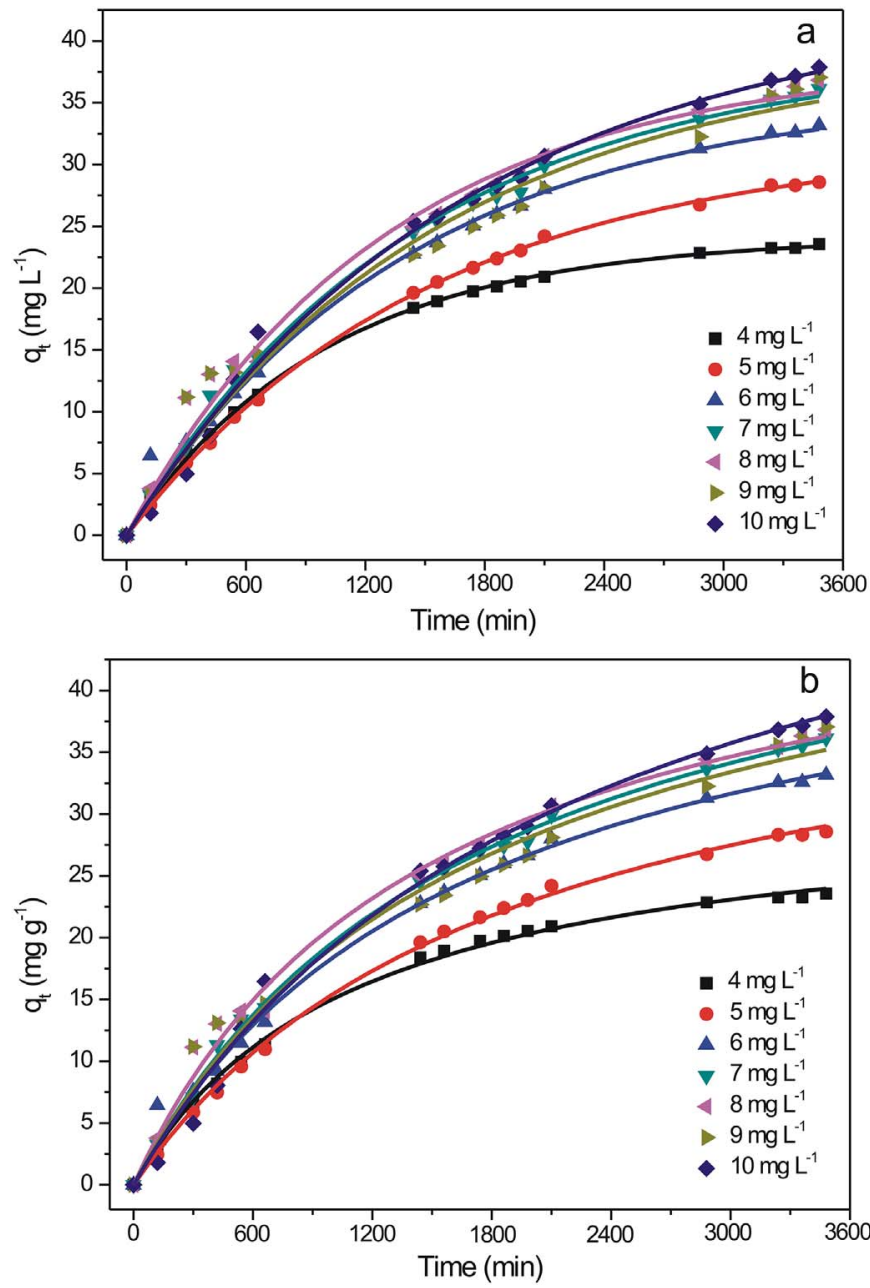

Fig. 7. Temporal evolution of the quantities of MB dye adsorbed by the CPN immersed in aqueous solutions containing different concentrations of dye. The continuous lines represent the best fits of the experimental data by (a) the pseudo-first order model and (b) the pseudo-second order model.

assess the kinetics of adsorption of the MB dye by the CPN hybrid matrix. The experimental data were fitted by the Lagergren pseudo-first order and pseudo-second order equations (Günay et al., 2007; Vargas et al., 2011).

$q_{t}=q_{e}\left[1-\exp \left(-k_{1} t\right)\right]$

$q_{t}=\frac{k_{2} q_{e}^{2} t}{\left(1+k_{2} q_{e} t\right)}$

where $q_{e}$ is the mass of dye adsorbed per gram at equilibrium, and $k_{1}$ $\left(\mathrm{min}^{-1}\right)$ and $k_{2}\left(\mathrm{~g} \mathrm{mg}^{-1} \mathrm{~min}^{-1}\right)$ are the first and second order

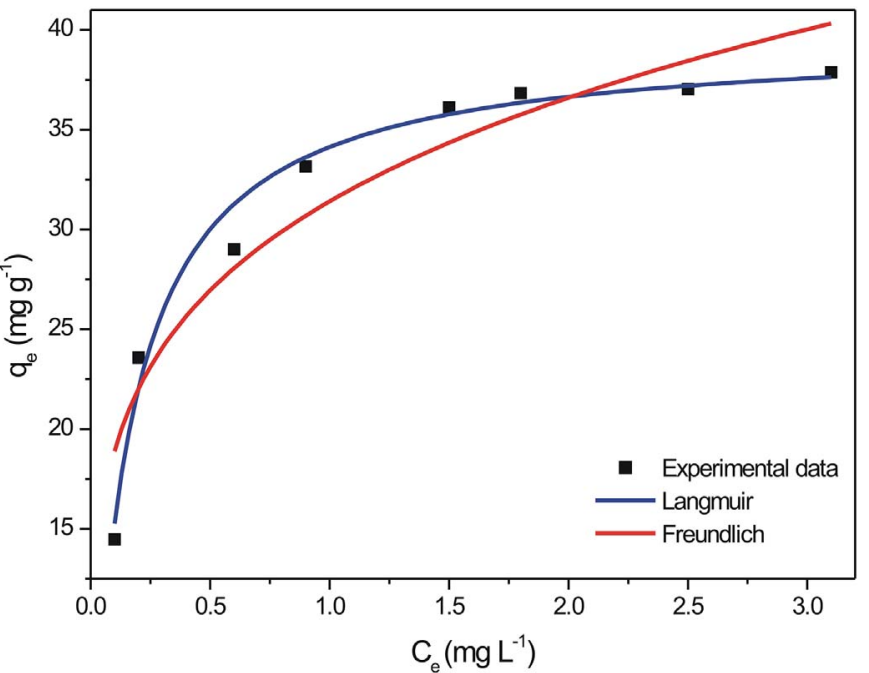

Fig. 8. Langmuir and Freundlich models for the adsorption of MB by the CPN.

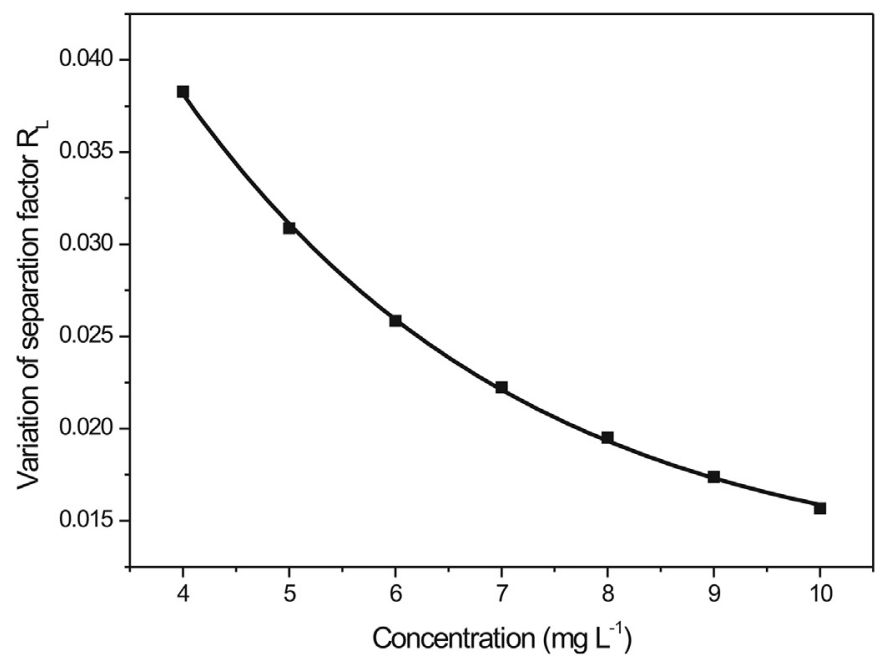

Fig. 9. Variation of the separation factor $\left(R_{L}\right)$ according to the initial MB dye solution concentration.

adsorption rate constants, respectively (Moura et al., 2015; Zhou et al., 2014).

The parameters obtained from the nonlinear least squares fitting procedure for the two kinetic models are shown in Table 2. In both cases, the correlation coefficients $\left(\mathrm{R}^{2}\right)$ were higher than 0.99 for all concentrations. The experimental values $\left(\mathrm{q}_{\mathrm{e}}\right.$ exp $)$, assumed to be equal to the asymptotic $q_{e}$ cal values corresponding to the saturations observed for the solutions with different initial concentrations, were closer to the values calculated using the pseudo-first order model, indicating that

Table 2

Kinetic parameters for the adsorption of MB by the CPN.

\begin{tabular}{|c|c|c|c|c|c|c|c|}
\hline \multirow{2}{*}{$\begin{array}{l}\mathrm{C}_{\mathrm{o}} \\
\left(\mathrm{mg} \mathrm{L} \mathrm{L}^{-1}\right)\end{array}$} & \multirow{2}{*}{$\begin{array}{l}\mathrm{q}_{\mathrm{e}} \exp \\
\left(\mathrm{mg} \mathrm{g}^{-1}\right)\end{array}$} & \multicolumn{3}{|c|}{ Pseudo-first order } & \multicolumn{3}{|c|}{ Pseudo-second order } \\
\hline & & $\begin{array}{l}\mathrm{k}_{1} 10^{-4} \\
\left(\min ^{-1}\right)\end{array}$ & $\begin{array}{l}\mathrm{q}_{\mathrm{e} \mathrm{calc}} \\
\left(\mathrm{mg} \mathrm{g}^{-1}\right)\end{array}$ & $\mathrm{R}^{2}$ & $\begin{array}{l}\mathrm{k}_{2} 10^{-4} \\
\left(\mathrm{~g} \mathrm{mg}^{-1} \min ^{-1}\right)\end{array}$ & $\begin{array}{l}\mathrm{q}_{\mathrm{e} \mathrm{calc}} \\
\left(\mathrm{mg} \mathrm{g}^{-1}\right)\end{array}$ & $\mathrm{R}^{2}$ \\
\hline 4 & 23.58 & 10.10 & 24.15 & 0.9992 & 0.29 & 31.54 & 0.9976 \\
\hline 5 & 28.57 & 6.57 & 31.89 & 0.9997 & 0.12 & 45.15 & 0.9985 \\
\hline 6 & 33.17 & 7.74 & 35.92 & 0.9917 & 0.12 & 49.51 & 0.9929 \\
\hline 7 & 36.12 & 7.01 & 39.11 & 0.9964 & 0.10 & 54.23 & 0.9983 \\
\hline 8 & 36.83 & 8.14 & 38.49 & 0.9879 & 0.13 & 51.68 & 0.9931 \\
\hline 9 & 37.04 & 7.11 & 39.30 & 0.9692 & 0.11 & 52.99 & 0.9792 \\
\hline 10 & 37.88 & 5.69 & 43.01 & 0.9932 & 0.07 & 62.21 & 0.9927 \\
\hline
\end{tabular}


this model provided the best description of the experimental data (Fig. 7a). The expected invariance of the rate constant $\left(k_{1}=0.001 \pm 0.0005 \mathrm{~min}^{-1}\right)$ was observed for all $\mathrm{MB}$ dye concentrations higher than $4 \mathrm{mg} \mathrm{L}^{-1}$. The higher $k_{1}$ value of $0.001 \mathrm{~min}^{-1}$ obtained for the solution with the lower dye concentration $\left(\mathrm{C}_{0}=4 \mathrm{mg} \mathrm{L}^{-1}\right)$ provided evidence of a diffusional contribution to the flux of the aqueous MB dye solution into the CPN matrix.

The experimental $\mathrm{MB}$ dye solution concentrations at equilibrium $\left(C_{e}\right)$ were analyzed using the Langmuir (Eq. 4) and Freundlich (Eq. 5) isotherms:

$q_{e}=\frac{q_{m} k_{L} C_{e}}{\left(1+k_{L} C_{e}\right)}$

$q_{e}=k_{F} C_{e^{\frac{1}{n}}}$

where $\mathrm{q}_{\mathrm{m}}$ is the monolayer adsorption capacity $\left(\mathrm{mg} \mathrm{g}^{-1}\right), \mathrm{k}_{\mathrm{L}}$ is the binding constant $\left(\mathrm{L} \mathrm{mg}^{-1}\right)$ related to the heat of adsorption, $\mathrm{n}$ expresses the dependency of the adsorption heat on the surface occupation, and $\mathrm{k}_{\mathrm{F}}$ is a constant related to the adsorption capacity $\left(\left(\mathrm{mg} \mathrm{g}^{-1}\right)\left(\mathrm{L} \mathrm{mg}^{-1}\right)^{1 /}\right.$ $\left.{ }^{n}\right)$. The best fits achieved using the two models are shown by the continuous lines in Fig. 8. The Langmuir model provided a satisfactory fit for the entire dye concentration range, with a correlation coefficient $\left(\mathrm{R}^{2}\right)$ higher than 0.987 . This indicated that the adsorption process was limited to a monolayer of the dye, and that at steady state equilibrium all the surface adsorption sites had comparable heats of adsorption. Considering the heterogeneity of the CPN organic-inorganic matrix, the good fit obtained with the Langmuir model provided strong evidence that the surface adsorption sites mainly belonged to the Mt.The monolayer adsorption capacity $\left(\mathrm{q}_{\mathrm{m}}\right)$ and the binding constant $\left(\mathrm{k}_{\mathrm{L}}\right)$ determined from the Langmuir model fitting of the experimental dye adsorption isotherms were $39.6 \mathrm{mg} \mathrm{g}^{-1}$ and $6.28 \mathrm{~L} \mathrm{mg}^{-1}$, respectively. The $\mathrm{k}_{\mathrm{L}}$ value was used to calculate the dimensionless separation factor constant, $R_{\mathrm{L}}$, defined by the following relationship (Hall et al., 1966):

$R_{L}=\frac{1}{\left(1+k_{L} C_{0}\right)}$

This essential element of the Langmuir isotherm provided information about the favorability of the adsorption process. The $R_{L}$ value has four possible adsorption classifications: $0<R_{L}<1$ (favorable); $R_{L}>1$ (unfavorable); $R_{L}=1$ (linear); and $R_{L}=0$ (irreversible) (Bulut and Karaer, 2015; Fil et al., 2012; Saha et al., 2011). The variation of $R_{L}$ with the initial MB dye solution concentration is shown in Fig. 9. The $R_{L}$ values were in the range from 0 to 1 , indicative of favorable adsorption of $\mathrm{MB}$ on the CPN. The $\mathrm{R}_{\mathrm{L}}$ value approached zero as $\mathrm{C}_{0}$ increased, indicating that MB adsorption was less favorable at higher initial concentrations.

\section{Conclusions}

A CPN was effectively synthesized by the sol-gel method. XRD analysis of the nanocomposite showed that the Mt. (001) basal reflection was shifted to smaller angles, suggesting intercalation of PEO between the silicate layers. Use of SAXS to evaluate nanostructural changes during immersion of the nanocomposite in dye solutions and in water revealed similar decrease of the Mt. peak area and increase of FWHM, indicating that the adsorption of water led to a reduction of the Mt. crystallite size. UV-Vis absorption measurements showed that the nanocomposite removed $>69 \%$ of the cationic dye after $58 \mathrm{~h}$ of immersion. The best fits to the experimental adsorption data were provided by the pseudo-first order kinetic model and the Langmuir equilibrium model. The results indicated that the nanocomposites are potentially applicable as easily recovered adsorbents of cationic dyes present in contaminated waters, due to the combined properties of Mt. and the U-PEO hybrid.

\section{Acknowledgments}

This work was supported by the Brazilian agencies CAPES (INCT465593/2014-3), CNPq (304900/2011-7), and FAPESP (INCT465593/2014-3). The authors wish to thank the Brazilian Synchrotron Light Laboratory (LNLS) for providing access to the SAXS1 beamline.

\section{Appendix A. Supplementary data}

Supplementary data to this article can be found online at https:// doi.org/10.1016/j.clay.2017.11.009.

\section{References}

Aguiar, J.E., Cecilia, J.A., Tavares, P.A.S., Azevedo, D.C.S., Castellón, E.R., Lucena, S.M.P., Silva, I.J., 2017. Adsorption study of reactive dyes onto porous clay heterostructures. Appl. Clay Sci. 135, 35-44. http://dx.doi.org/10.1016/j.clay.2016.09. 001.

Aladağ, E., Fil, B.A., Boncukcuoğlu, R., Sözüdoğru, O., Yılmaz, A.E., 2014. Adsorption of methyl violet dye, a textile industry effluent onto montmorillonite-batch study. J. Dispers. Sci. Technol. 35, 1737-1744. http://dx.doi.org/10.1080/01932691.2013. 873865.

Allègre, C., Moulin, P., Maisseu, M., Charbit, F., 2006. Treatment and reuse of reactive dyeing effluents. J. Membr. Sci. 269, 15-34. http://dx.doi.org/10.1016/j.memsci. 2005.06.014.

Almeida, C.A.P., Debacher, N.A., Downs, A.J., Cottet, L., Mello, C.A.D., 2009. Removal of methylene blue from colored effluents by adsorption on montmorillonite clay. J. Colloid Interface Sci. 332, 46-53. http://dx.doi.org/10.1016/j.jcis.2008.12.012.

Àngels Olivella, M., Fiol, N., de la Torre, F., Poch, J., Villaescusa, I., 2012. A mechanistic approach to methylene blue sorption on two vegetable wastes: cork bark and grape stalks. Bioresources 7, 3340-3354. doi: http://dx.doi.org/10.15376/biores.7.3.33403354.

Bekiari, V., Lianos, P., 2006. Ureasil gels as a highly efficient adsorbent for water purification. Chem. Mater. 18, 4142-4146. http://dx.doi.org/10.1021/cm060215t.

Bergmann, K., O'Konski, C.T., 1963. A spectroscopic study of methylene blue monomer, dimer, and complexes with montmorillonite. J. Phys. Chem. 67, 2169-2177. http:// dx.doi.org/10.1021/j100804a048.

Bhatnagar, A., Sillanpää, M., 2010. Utilization of agro-industrial and municipal waste materials as potential adsorbents for water treatment-a review. Chem. Eng. J. http:// dx.doi.org/10.1016/j.cej.2010.01.007.

Brinker, J.C., Scherer, G., 1990. Sol-Gel Science: The Physics and Chemistry of Sol-Gel Processing. Advanced Materials, Boston. http://dx.doi.org/10.1186/1471-2105-8444.

Bulut, Y., Karaer, H., 2015. Adsorption of methylene blue from aqueous solution by crosslinked chitosan/bentonite composite. J. Dispers. Sci. Technol. 36, 61-67. http:// dx.doi.org/10.1080/01932691.2014.888004.

Chaker, J.A., Dahmouche, K., Santilli, C.V., Pulcinelli, S.H., Goncalves, M.C., Gomes Correia, S.M., De Zea Bermudez, V., Judeinstein, P., Briois, V., Craievich, A.F., 2006. Local and nanoscopic structure of potassium triflate-doped siloxane-polyoxyethylene ormolytes. J. Non-Cryst. Solids 352, 3457-3462. http://dx.doi.org/10.1016/j. jnoncrysol.2006.02.109.

Chieng, B.W., Ibrahim, N.A., Wan Yunus, W.M.Z., 2010. Effect of organo-modified montmorillonite on poly(butylene succinate)/poly(butylene adipate-co-terephthalate) nanocomposites. Express Polym Lett 4, 404-414. http://dx.doi.org/10. 3144/expresspolymlett.2010.51.

Crini, G., 2006. Non-conventional low-cost adsorbents for dye removal: a review. Bioresour. Technol. http://dx.doi.org/10.1016/j.biortech.2005.05.001.

Feng, M., You, W., Wu, Z., Chen, Q., Zhan, H., 2013. Mildly alkaline preparation and methylene blue adsorption capacity of hierarchical flower-like sodium titanate. ACS Appl. Mater. Interfaces 5, 12654-12662. http://dx.doi.org/10.1021/am404011k.

Fil, B.A., Özmetin, C., Korkmaz, M., 2012. Cationic dye (methylene blue) removal from aqueous solution by montmorillonite. Bull. Kor. Chem. Soc. 33, 3184-3190. http:// dx.doi.org/10.5012/bkcs.2012.33.10.3184.

Günay, A., Arslankaya, E., Tosun, I., 2007. Lead removal from aqueous solution by natural and pretreated clinoptilolite: adsorption equilibrium and kinetics. J. Hazard. Mater. 146, 362-371. http://dx.doi.org/10.1016/j.jhazmat.2006.12.034.

Gunay, A., Ersoy, B., Dikmen, S., Evcin, A., 2013. Investigation of equilibrium, kinetic, thermodynamic and mechanism of Basic Blue 16 adsorption by montmorillonitic clay. Adsorption 757-768. http://dx.doi.org/10.1007/s10450-013-9509-4.

Hajjaji, W., Pullar, R.C., Labrincha, J.A., Rocha, F., 2016. Aqueous acid Orange 7 dye removal by clay and red mud mixes. Appl. Clay Sci. 126, 197-206. http://dx.doi.org/ 10.1016/j.clay.2016.03.016.

Hall, K.R., Eagleton, L.C., Andreas Acrivos, T.V., 1966. Pore- and solid-diffusion kinetics in fixed-bed adsorption under constant-pattern conditions. Ind. Eng. Chem. Fundam. 5, 212-223. http://dx.doi.org/10.1021/i160018a011.

Hegyesi, N., Vad, R.T., Pukánszky, B., 2017. Determination of the specific surface area of layered silicates by methylene blue adsorption: the role of structure, $\mathrm{pH}$ and layer charge. Appl. Clay Sci. 146, 50-55. http://dx.doi.org/10.1016/j.clay.2017.05.007.

Hikosaka, M.Y., Pulcinelli, S.H., Santilli, C.V., Dahmouche, K., Craievich, A.F., 2006. Montmorillonite (MMT) effect on the structure of poly(oxyethylene) (PEO)-MMT 
nanocomposites and silica-PEO-MMT hybrid materials. J. Non-Cryst. Solids 352, 3705-3710. http://dx.doi.org/10.1016/j.jnoncrysol.2006.02.124.

Kariminezhad, H., Habibi, M., Mirzababayi, N., 2015. Nanosized ZSM-5 will improve photodynamic therapy using methylene blue. J. Photochem. Photobiol. B Biol. 148, 107-112. http://dx.doi.org/10.1016/j.jphotobiol.2015.03.013.

Madejová, J., 2003. FTIR techniques in clay mineral studies. Vib. Spectrosc. 31, 1-10 http://dx.doi.org/10.1016/S0924-2031(02)00065-6.

Molina, E.F., Parreira, R.L.T., De Faria, E.H., De Carvalho, H.W.P., Caramori, G.F., Coimbra, D.F., Nassar, E.J., Ciuffi, K.J., 2014. Ureasil-poly(ethylene oxide) hybrid matrix for selective adsorption and separation of dyes from water. Langmuir 30 , 3857-3868. http://dx.doi.org/10.1021/la404812e.

Moura, A.L.a., de Oliveira, L.K., Ciuffi, K.J., Molina, E.F., 2015. Influence of the hydrophilic/hydrophobic nature of polyetheramines on the interaction between amine-alcohol-silicate hybrids and anionic dyes for effective water cleaning. J. Mater. Chem. A 3, 16020-16032. http://dx.doi.org/10.1039/C5TA04022A.

Pavia, D., Lampman, G., Kriz, G., Vyvyan, J., 2012. Introdução à espectroscopia. Cengage Learning. http://dx.doi.org/10.1590/S0100-40422007000700048.

Saha, B., Das, S., Saikia, J., Das, G., 2011. Preferential and enhanced adsorption of different dyes on iron oxide nanoparticles: a comparative study. J. Phys. Chem. C. http://dx.doi.org/10.1021/jp109258f.

Santilli, C.V., Chiavacci, L.A., Lopes, L., Pulcinelli, S.H., Oliveira, A.G., 2009. Controlled drug release from Ureasil - polyether hybrid materials. Chem. Mater. 21, 463-467. http://dx.doi.org/10.1021/cm801899u.

dos Santos, R.M.M., Gonçalves, R.G.L., Constantino, V.R.L., Santilli, C.V., Borges, P.D. Tronto, J., Pinto, F.G., 2017. Adsorption of acid yellow 42 dye on calcined layered double hydroxide: effect of time, concentration, $\mathrm{pH}$ and temperature. Appl. Clay Sci. 140, 132-139. http://dx.doi.org/10.1016/j.clay.2017.02.005.
Strawhecker, K.E., Manias, E., 2003. Crystallization behavior of poly(ethylene oxide) in the presence of $\mathrm{Na}+$ montmorillonite fillers. Chem. Mater. 15, 844-849. http://dx. doi.org/10.1021/cm0212865.

Unuabonah, E.I., Taubert, A., 2014. Clay-polymer nanocomposites (CPNs): adsorbents of the future for water treatment. Appl. Clay Sci. 99, 83-92. http://dx.doi.org/10.1016/ j.clay.2014.06.016.

Validi, M., Bazgir, S., Rashidi, A., Yazdanshenas, M.E., 2012. Intercalation of methylene blue into montmorillonite at different conditions: an approach for preparing claybased nanopigments. Ceramics-Silikáty 56, 152-158.

Vargas, A.M.M., Cazetta, A.L., Kunita, M.H., Silva, T.L., Almeida, V.C., 2011. Adsorption of methylene blue on activated carbon produced from flamboyant pods (Delonix regia): study of adsorption isotherms and kinetic models. Chem. Eng. J. 168, 722-730. http://dx.doi.org/10.1016/j.cej.2011.01.067.

de Zea Bermudez, V., Carlos, L.D., Alcácer, L., 1999. Sol-gel derived urea cross-linked organically modified silicates. 1. Room temperature mid-infrared spectra. Chem. Mater. 11, 569-580. http://dx.doi.org/10.1021/cm980372v.

Zhang, Q., Zhang, T., He, T., Chen, L., 2014. Removal of crystal violet by clay/PNIPAm nanocomposite hydrogels with various clay contents. Appl. Clay Sci. 90, 1-5. http:// dx.doi.org/10.1016/j.clay.2014.01.003.

Zhou, Q., Lin, X., Li, B., Luo, X., 2014. Fluoride adsorption from aqueous solution by aluminum alginate particles prepared via electrostatic spinning device. Chem. Eng. J. 256, 306-315. http://dx.doi.org/10.1016/j.cej.2014.06.101.

Zhu, R., Chen, Q., Liu, H., Ge, F., Zhu, L., Zhu, J., He, H., 2014. Montmorillonite as a multifunctional adsorbent can simultaneously remove crystal violet, cetyltrimethylammonium, and 2-naphthol from water. Appl. Clay Sci. 88-89, 33-38. http://dx.doi.org/10.1016/j.clay.2013.12.010. 